\title{
A coordenação pedagógica, a formação continuada e a diversidade étnico-racial: um desafio
}

\section{Pedagogical coordination, continued education and ethnic-racial diversity: a challenge}

\author{
Bartolina Ramalho Catanante* \\ Lucimar Rosa Dias**
}

\begin{abstract}
RESUMO
Este artigo almeja discutir os desafios colocados ao trabalho do(a) coordenador(a) pedagógico(a) como responsável pela formação continuada nas instituições escolares e a necessária inclusão nessas atividades da educação para as relações étnico-raciais, conforme determina as Diretrizes Curriculares para a Formação Inicial e Continuada de Professores. A nós nos interessa compreender o que se espera desse(a) profissional na articulação do papel formador com as normativas que assegurem o direito a todos (as) de acessarem uma educação que contemple a diversidade étnico-racial. Nossa conclusão é que, se não for acompanhada de apoio institucional, a carga de responsabilidade atribuída à formação realizada no lócus da escola pelo(a) coordenador(a) dificilmente levará a uma educação que promova a igualdade racial tal qual prevista nas normativas.
\end{abstract}

Palavras-chave: Formação de professores. Coordenação pedagógica. Diversidade étnico-racial.

DOI: $10.1590 / 0104-4060.51130$

* Universidade Estadual de Mato Grosso do Sul. Campo Grande, Mato Grosso do Sul, Brasil. Unidade Universitária de Campo Grande. Rua dos Dentistas, 500. Arnaldo Estevão de Figueiredo. CEP: 79043250. E-mail: bartolina@uems.br

** Universidade Federal do Paraná. Setor de Educação. Curitiba, Paraná, Brasil. Rua General Carneiro, 460. Centro. CEP: 80060-150. E-mail: lucimar_dias@uol.com.br 


\begin{abstract}
This article looks at the challenges of the work of the pedagogical coordinator during the implementation of activities related to racial and ethnic relations, such as provided for in the Curriculum Guidelines for Teacher Education. The goal is to understand the expectations around these education workers when it comes to articulating their role in a way that guarantees the rights to all regarding the access to an education that encompasses ethnic and racial diversity. Upon examination of this process, it becomes clear that the coordinator's responsibility lacks institutional support and accountability necessary to produce sound educational public policies. Thus, one will hardly have an education that promotes racial equality as envisaged by the regulations.
\end{abstract}

Keywords: Teacher training. Pedagogical coordination. Ethnic-racial diversity.

\title{
Introdução
}

O objetivo deste artigo é discutir o papel do(a) coordenador(a) pedagógico(a) frente ao desafio de colaborar no processo formativo de professores(as) para atuarem com a (re)educação das relações étnico-raciais. Como a própria temática anuncia, parte-se do pressuposto que este(a) profissional deve ter uma práxis que procure contemplar uma perspectiva inclusiva na ação como formador(a).

Tal assertiva compreende que esse profissional exerce uma função-meio desencadeadora de práticas pedagógicas capazes de modificar a realidade hierarquizadora, discriminatória e preconceituosa, observada no cotidiano de muitas instituições educacionais. Não há contestação quanto ao papel de formador(a) que ora este(a) profissional assume na nova configuração das relações de trabalho no âmbito educacional. No entanto, é fundamental refletirmos sobre quais são as atribuições atuais e quais as condições possíveis para que elas se realizem.

$\mathrm{O}$ (a) coordenador(a) pedagógico(a) é aquele(a) profissional que coordena o trabalho realizado na escola de forma que este não se torne individualista e desarticulado com a realidade e as necessidades do(a) professor(a) e dos(as) estudantes. Para Pinto (2011, p. 77), o(a) coordenador(a) pedagógico(a) é

O profissional de ensino que dá suporte ao trabalho docente, que deve ter domínio dos procedimentos que envolvem o processo de ensino e apren- 
dizagem que acontece formalmente na sala de aula, mas do mesmo modo deve ter domínio dos demais procedimentos que envolvem a totalidade das atividades educativas que ocorrem em toda a escola e que estão direta ou indiretamente relacionadas com as práticas educativas da sala de aula.

Este(a) profissional também é um(a) docente que deve saber da realidade de uma sala de aula, tendo a obrigação de lutar contra tudo o que desvaloriza a escola e o trabalho do(a) professor(a), porém, apesar de docente, o seu exercício ocorre em outros espaços que não são exatamente os da sala de aula. Embora esse fato pareça óbvio, nem sempre foi assim. O Parecer $n^{\circ} 252$, de 1969, complementar à Lei da Reforma Universitária (Lei no 5540/1968), que instituiu as habilitações do curso de Pedagogia - entre as quais a de supervisor escolar, tinha em sua concepção a formação de profissionais não docentes, os chamados "especialistas em educação". Segundo Pinto (2011), o contexto de formação desses profissionais foi de caráter tecnicista e sua principal função era supervisionar o trabalho do(a) professor(a). Já a orientação educacional foi oficialmente introduzida no país "em 1942, na Lei Orgânica do Ensino Secundário. Desde sua criação, foi prevista como um serviço educacional a ser desenvolvido nas escolas junto aos alunos" (PINTO, 2011, p. 85).

Essas funções, antes distintas com atuações específicas no curso da história da constituição profissional do Pedagogo, vão se fortalecendo até que o aspecto da docência ganha total relevância no processo formativo desse profissional, no entanto, no fazer escolar, no cotidiano, o que era realizado pelos especialistas passa a ser tarefa da coordenação pedagógica, função muitas vezes exercida por profissionais que não possuem a formação inicial no curso de licenciatura de Pedagogia, o que acarretou várias problematizações em sua configuração profissional, já que muito do que se faz no exercício da função é tratado no curso de Pedagogia, mas não em outras licenciaturas.

A mudança na forma de organização da produção capitalista, o toyotismo, também contribuiu para o processo de novas atribuições ao profissional da coordenação pedagógica, muitos dos princípios dessa concepção de trabalho envolvem conceitos de administração participativa, trabalho em equipe, multifuncionalidade, flexibilidade e estímulo à iniciativa no trabalho. Essas atribuições são facilmente identificadas ao constatarmos o que se pede em editais de concurso em relação ao perfil do coordenador(a) pedagógico(a).

Segundo Kuenzer (2002, p. 49), os sistemas reorganizaram o trabalho pedagógico "substituindo os especialistas - administrador, supervisor, orientador - pelo pedagogo unitário, profissional multitarefa", ou seja, um único profissional ganhou novas tarefas. Nesse contexto, se, por um lado, ganhamos na concepção 
de trabalhador unitário que concebe todo o processo educativo e não apenas um fragmento dele, por outro lado, perdemos nas condições de trabalho que foram precarizadas com o aumento de atribuições sem a sua melhoria. Segundo Placco, Almeida e Souza (2012, p. 766), "as dificuldades enfrentadas por esse profissional envolvem, assim, a remuneração, a grande quantidade de tarefas, o pouco tempo para realizá-las e a falta de formação específica".

São várias as atribuições que devem ser desenvolvidas pelo(a) coordenador(a) pedagógico(a) dentro de uma instituição escolar, porém o que lhe dará condições de realizá-las com qualidade, sem se perder em imputações burocráticas que não contribuem para o processo de produção do conhecimento no interior das instituições, será a forma como organiza o trabalho pedagógico. A partir dos anos 1980, observamos a constituição e a ampliação da atuação do(a) coordenador(a) pedagógico(a) no ambiente escolar. Segundo Domingues (2014, p. 25), nesta década

As principais questões educativas diziam respeito à melhoria da qualidade do ensino com a diminuição da repetência e da evasão escolar. Aquela década, calcada por um movimento pós-ditadura, foi ampla em debates e produções científicas que, somadas às alterações legais como a Constituição Federal de 1988, trouxe novos ares e novas perspectivas para a educação nacional, impulsionando o movimento de reforma educativa nos estados. Desde então amplia-se as demandas de trabalho para o coordenador pedagógico, bem como as pesquisas sobre a atuação desse profissional $[\ldots]$.

O trabalho deste(a) profissional deve contemplar estudantes, familiares, professores(as) e direção escolar, buscando no trabalho coletivo meios de integrar todos esses agentes, com o objetivo de dar maior sentido e qualidade à prática educativa (PINTO, 2011). Acreditamos que seja essa a "janela" de oportunidade para que o trabalho com a diversidade étnico-racial aconteça por meio da ação construtiva desse(a) profissional nos processos de formação continuada. Dizemos isso porque a legislação que trata da formação inicial e continuada indica que são:

[...] aportes e concepções fundamentais para a melhoria da formação inicial e continuda (sic!) e suas dinâmicas formativas: [...] o respeito à liberdade e o apreço à tolerância; [...] o respeito e a valorização da di- 
versidade étnico-racial, entre outros, constituem princípios vitais para a melhoria e democratização da gestão e do ensino. (BRASIL, 2015, p. 21).

É, portanto, como uma exigência legal que a diversidade étnico-racial se insere como uma das prerrogativas da formação continuada. Porém é importante compreender que, para a sua concretização, é necessário que a ação educativa do(a) coordenador(a) pedagógico(a) vá para além do legalismo, reconhecendo que tratar da Educação para as Relações Étnico-Raciais (ERER), em processos de formação continuada, relaciona-se diretamente com o sentido ético do seu papel de agente propulsor de práticas emancipatórias no ambiente escolar. Ou seja, sua ação implica reconhecer que os sujeitos da escola são diversos e que estão imersos em uma sociedade que costuma valorizar determinadas marcas de pertencimento. Portanto, é também tarefa sua como formado(a) discutir o papel do(a) professor(a) no processo educativo de forma que altere as relações mirando o bem comum, a igualdade. Paulo Freire em "Cartas aos educadores" nos convoca a refletirmos sobre a dialética do fazer no processo educativo. Diz ele

Partamos da experiência de aprender, de conhecer, por parte de quem se prepara para a tarefa docente, que envolve necessariamente estudar. Obviamente, minha intenção não é escrever prescrições que devam ser rigorosamente seguidas, o que significaria uma chocante contradição com tudo o que falei até agora. Pelo contrário, o que me interessa aqui, de acordo com o espírito mesmo deste livro, é desafiar seus leitores e leitoras em torno de certos pontos ou aspectos, insistindo em que há sempre algo diferente a fazer na nossa cotidianidade educativa, quer dela participemos como aprendizes, e, portanto, ensinantes, ou como ensinantes e, por isso, aprendizes também. (FREIRE, 2001, p. 260).

Sendo assim, o(a) coordenador(a) pedagógico(a) para desenvolver ações formativas que discutam e problematizem a diversidade étnico-racial ocupará ora o papel de "ensinante" ora o de "aprendiz", porque estará lidando com "matéria" para a qual ele(a) mesmo(a) pode não ter tido nenhuma orientação inicial de como o fazer. No entanto, está previsto nas normativas atuais que também este ponto deve ser contemplado. Qual é a postura que o(a) coordenador(a) deve ter diante desse vazio teórico? Recuar da sua tarefa ou enfrentar o dever ético de construir junto com os(as) sujeitos(as) o espaço escolar como um lugar de respeito às diferenças? 
Certamente o(a) profissional precisa fazer uma escolha e, claro, defendemos que a segunda opção é a melhor, pois acolhe a ideia de que se aprende e se ensina sobre o tema com outros agentes sociais, especialmente com aqueles(as) que no cotidiano da vida estejam lidando diretamente com questões relativas à diversidade étnico-racial, seja por serem ativistas sociais, seja por serem eles(as) os próprios(as) viventes da experiência. É nesse processo de escuta do(a) outro(a) que se faz uma educação para a diversidade étnico-racial e acreditamos que seja possível realizar a formação continuada.

No entanto, como diz Paulo Freire (2001, p. 260), "Partamos da experiência de aprender, de conhecer, por parte de quem se prepara para a tarefa docente, que envolve necessariamente estudar"; isto é, não se defende que o trato com a ERER seja a partir da espontaneidade, do senso comum, sem apuro teórico; ao contrário, como outro campo do conhecimento qualquer, ele possui conceitos, pesquisas, acúmulo de conhecimentos. É nessa perspectiva que o(a) coordenador(a) pedagógico(a) deve atuar quando insistimos que a organização da formação continuada realizada por esse(a) profissional deve ter a dimensão da diversidade étnico-racial articulando a "leitura do mundo, a leitura da palavra", ou seja,

A leitura da palavra, fazendo-se também em busca da compreensão do texto e, portanto, dos objetos nele referidos, nos remete agora à leitura anterior do mundo. O que me parece fundamental deixar claro é que a leitura do mundo que é feita a partir da experiência sensorial não basta. Mas, por outro lado, não pode ser desprezada como inferior pela leitura feita a partir do mundo abstrato dos conceitos que vai da generalização ao tangível. (FREIRE, 2001, p. 261).

A formação continuada organizada pelo(a) coordenador(a) pode favorecer discussões a partir de suas práticas, tendo como referência o seu local de trabalho e a troca de experiência entre os(as) colegas, é aconselhável buscar por teorias que sustentem essas práticas. Assim, o que lhes dará condições de realizar com qualidade suas atribuições será não somente sua experiência como professor(a), mas também seus estudos, leituras e reflexões. Segundo Ghedin (2002), a experiência prática é importante quando possibilita um salto para além da prática, buscando fundamentações teóricas que as subsidiem.

O fato é que há legislação suficiente que ampara o(a) coordenador(a) pedagógico(a) na constituição de uma política de formação continuada em uma perspectiva que reafirma a formação docente inicial e continuada comprometida 
com o respeito pelo outro. O que falta é uma ação institucional que possa amparar esse(a) profissional, dando-lhe as condições necessárias para atuar neste campo. Seria importante ter materiais produzidos que dialogassem diretamente com esse(a) profissional para que pudesse se sentir seguro no trato com o tema.

Ignácio (2008), em sua pesquisa na qual aplicou questionário a coordenadores(as) do município de São Paulo sobre o trabalho que realizavam para aplicar a legislação que trata da história e da cultura afro-brasileira, constata que não é muito fácil para o(a) coordenador(a) ultrapassar os limites estruturais de uma sociedade racista e colocar em prática princípios éticos que até aparecem em seus discursos, mas que pouco se expressam em suas práticas. Segundo a autora

\begin{abstract}
Da perspectiva do professor coordenador, constata-se a questão do ensino de história e cultura afro-brasileira carregada de valores eurocêntricos, sendo que a grande maioria dos sujeitos investigados não o reconhece como contribuição para toda comunidade escolar, embora afirmem que o processo de formação da identidade dos alunos deve acontecer independente do pertencimento racial. O comportamento do professor coordenador pedagógico durante a coleta de dados, nas respostas enunciadas no questionário e principalmente na resistência em não participar da pesquisa, se omitindo em não registrar sua opinião sobre as relações raciais, revelam que esse profissional compreende o tratamento desta temática como desnecessária, pois acreditam serem suficientemente contempladas ao discutir de forma geral temas como ética e cidadania. Isso revela que este profissional não reconhece especificidades que precisam ser consideradas referente à negritude. Afinal de contas os dados continuam demonstrando, como explicitados durante esta pesquisa, que alunos negros e afros-descendentes continuam ocupando níveis de aproveitamento escolar inferior. (IGNÁCIO, 2008, p. 86).
\end{abstract}

Evidentemente os resultados da pesquisa de Ignácio (2008) não podem ser generalizados para todos(as) os coordenadores(as) do Brasil, mas eles revelam a força do racismo à brasileira, isto é, todos(as) sabemos que as relações políticas e pessoais são atravessadas por hierarquias que tomam o pertencimento étnico-racial como um dos critérios, mas se guarda um silêncio sobre isso, pelo menos, tenta-se, ou melhor, alguns tentam de alguma maneira evitar que se trate abertamente do tema. Como tão bem já explicou Oracy Nogueira (2007, p. 299): 
Assim, no Brasil, não é de bom tom "puxar o assunto da cor", diante de uma pessoa preta ou parda. Evita-se a referência à cor, do mesmo modo como se evitaria a referência a qualquer outro assunto capaz de ferir a susceptibilidade do interlocutor - em geral, diz-se que "em casa de enforcado, não se fala em corda". Em contraposição, em qualquer contenda com uma pessoa de cor, a primeira ofensa que se lhe assaca é a referência a sua origem étnica".

Porém, a tentativa de silenciamento do tema não existe sem resistência, especialmente a realizada pelo Movimento Negro que tem revelado uma ação profícua de desconstrução dessa perspectiva. Passados nove anos da pesquisa de Ignácio (2008), somente houve acréscimo de normativas tratando do que estamos chamando de educação para as relações étnico-raciais. Podemos citar dois exemplos desse avanço normativo: o primeiro é que, em um dos objetivos apresentados pela Política Nacional de Formação de Profissionais à formação docente, se destaca o que pretende "promover a formação de professores(as) na perspectiva da educação integral, dos direitos humanos, da sustentabilidade ambiental e das relações étnico-raciais, com vistas à construção de ambiente escolar inclusivo e cooperativo" (BRASIL, 2009).

O segundo exemplo emblemático que podemos apresentar trata do último Plano Nacional de Educação (2014-2024), que considerou a ERER como uma das estratégias importantes das políticas educacionais para a melhoria da qualidade da educação básica (Meta 7), incluindo de forma inequívoca uma estratégia específica que visa

7.25) garantir nos currículos escolares conteúdos sobre a história e as culturas afro-brasileira e indígenas e implementar ações educacionais, nos termos das Leis ${ }^{\text {os }} 10.639$, de 9 de janeiro de 2003, e 11.645, de 10 de março de 2008, assegurando-se a implementação das respectivas diretrizes curriculares nacionais, por meio de ações colaborativas com fóruns de educação para a diversidade étnico-racial, conselhos escolares, equipes pedagógicas e a sociedade civil. (BRASIL, 2014).

A estratégia revela o significativo avanço no plano das definições políticas. Entretanto, isso não significa uma aplicação imediata da legislação, visto que requer outros elementos além dos marcos legais. Uma estrutura não se altera 
somente com leis, é preciso investimento em recursos humanos e materiais que consolidem as mudanças previstas na legislação.

Dessa forma, observamos que o desafio colocado à coordenação pedagógica para inclusão da ERER em ações formativas tem de vir acompanhado de alterações na formação inicial e de condições adequadas para que os processos formativos ocorram neste e o salto que se espera das instituições. Porém, não se pode esperar as condições ideais para dar início ao que se sabe que é necessário fazer. Por isso, é intrínseca a tensão entre o que se tem e o que precisa ser feito. $\mathrm{O}$ (a) coordenador(a) tem presente no dia a dia da escola a tarefa da formação continuada, ou seja, há o que fazer e, por isso, é imperioso que o exercício ético e comprometido desse(a) profissional se realize nas condições concretas existentes.

Se compete a esse(a) profissional trabalhar com o(a) professor(a), dando suporte ao trabalho a ser realizado junto à comunidade escolar. É uma das funções desse(a) profissional ajudar o coletivo a colocar em prática o combate a tudo aquilo que desumaniza essa comunidade, ou seja, a tarefa é possibilitar que todos(as) possam conviver com a diversidade numa dimensão de respeito e não de subordinação. Na literatura ainda são poucos os trabalhos que tratam de experiências concretas de formação de professores(as) realizadas por coordenadores(as) que tomaram como objeto a diversidade étnico-racial.

Nascimento (2015) investigou como as ações realizadas pela Comissão da Diversidade do Município de Pinhais influenciaram nas práticas formativas desenvolvidas pelos Coordenadores Pedagógicos junto aos educadores(as) dos Centros Municipais de Educação Infantil desse município. Segundo a autora, pode-se observar poucas pesquisas sobre a temática das relações raciais na educação infantil e a ausência de trabalhos que abordem as práticas de formação de Coordenadores(as) Pedagógicos(as) com foco em relações étnico-raciais na Educação Infantil.

Tal fato é um bom indicativo de que ou essas práticas não existem ou precisam ser devidamente problematizadas. Também nos alerta que, para o(a) coordenador(a) pedagógico cumprir as normativas no que se refere à diversidade étnico-racial nos processos de formação continuada, se conta na atualidade, sobretudo, com o compromisso individual, dada a falta de estratégias institucionais definidas pelos sistemas de educação municipais e estaduais que garantam de fato uma política que contemple devidamente o tema, em que pese as normativas serem mais do que suficientes para respaldar legalmente iniciativas desse porte. O desafio do(a) coordenador(a) é vencer a lógica de silenciamento do tema e abrir brechas para fazer acontecer. 


\section{REFERÊNCIAS}

BRASIL. Conselho Nacional de Educação. Resolução CNE/CP N ${ }^{\circ} 02 / 2015$, de $1^{\circ}$ de julho de 2015. Define as Diretrizes Curriculares Nacionais para a formação inicial em nível superior (cursos de licenciatura, cursos de formação pedagógica para graduados e cursos de segunda licenciatura) e para a formação continuada. Brasília, Diário Oficial da União, 02 jul. 2015. Disponível em: < http://pesquisa.in.gov.br/imprensa/j sp/visualiza/ index.jsp?data $=02 / 07 / 2015 \&$ jornal $=1 \&$ pagina $=8 \&$ totalArquivos $=72>$.

BRASIL. Lei No 13005, de 24 de junho de 2014. Aprova o Plano Nacional de Educação - PNE e dá outras providências. Diário Oficial da União, Brasília, DF, Edição Extra, 26 jun. 2014.

BRASIL. Ministério da Educação. Decreto No 6.755, de 29 de janeiro de 2009. Institui a Política Nacional de Formação de Profissionais do Magistério da Educação Básica, disciplina a atuação da Coordenação de Aperfeiçoamento de Pessoal de Nível Superior - CAPES no fomento a programas de formação inicial e continuada, e dá outras providências. Diário Oficial da União, Brasília, DF, 30 jan. 2009.

BRASIL. Ministério da Educação. Lei No 10.172, de 09 de janeiro de 2001. Plano Nacional de Educação e dá outras providências. Diário Oficial da União, Brasília, DF, 10 jan. 2001.

DOMINGUES, I. O/a coordenador/a pedagógico/a e a formação contínua do/a docente na escola. 1 ed. São Paulo: Cortez, 2014.

FREIRE, P. Carta de Paulo Freire aos professores: Ensinar, aprender: leitura do mundo, leitura da palavra. Estudos Avançados, São Paulo, v. 15, n. 42, p. 259-268, maio/ago. 2001.

GHEDIN, E. L. Professor reflexivo: da alienação da técnica à autonomia da crítica. In: PIMENTA, S. G.; GHEDIN, E. L. (Org.). Professor reflexivo no Brasil: gênese e crítica de um conceito. São Paulo: Cortez, 2002. p.129-150.

IGNÁCIO, V. B. S. O ensino da história e cultura afro-brasileira na óptica do coordenador pedagógico. 2008. 139 f. Dissertação (Mestrado em Educação: História, Política, Sociedade) - Pontifícia Universidade Católica de São Paulo, São Paulo, Biblioteca Depositária: PUC/SP, 2008.

KUENZER, A. Z. Trabalho pedagógico: da formação à unitariedade possível. In: AGUIAR, M. Â. da S.; FERREIRA, N. S. C. (Org.). Para onde vão a orientação e a supervisão educacional? 7. ed. Campinas: Papirus, 2002. p. 47-78.

NASCIMENTO, A. C. Z. do. Educação Infantil: Coordenação Pedagógica e a Educação das Relações Étnico-Raciais no município de Pinhais (PR). CONGRESSO DOS/ AS PESQUISADORES/AS NEGROS/AS DA REGIÃO SUL, 2., 2015, Curitiba, Resumo..., Disponível em: <https:/proceedings.galoa.com.br/copene-sul/trabalhos/ educacao-infantil-coordenacao-pedagogica-e-a-educacao-das-relacoes-etnico-raciais-no-municipio-de\#sthash.dLE2uBwZ.dpuf> Acesso em: 06 mar. 2017. 
NOGUEIRA, O. Preconceito racial de marca e preconceito racial de origem: sugestão de um quadro de referência para a interpretação do material sobre relações raciais no Brasil. Tempo Social, Revista de Sociologia da USP, São Paulo, v. 19, n. 1, p. 287-308, 2007.

PINTO, Umberto de Andrade. Pedagogia Escolar: Coordenação Pedagógica e Gestão Educacional. 1 ed. São Paulo: Cortez, 2011.

PLACCO, V. M. N. de S.; SOUZA, V. L. T. de; ALMEIDA, L. R. de. O/a coordenador/a pedagógico/a: aportes à proposição de políticas públicas. Caderno de pesquisa. São Paulo, v. 42, n. 147, p. 754-771, set./dez. 2012. Disponível em: <http://dx.doi.org/10.1590/ S0100-15742012000300006 >. Acesso em: 22 abr. 2015.

Texto recebido em 09 de março de 2017. Texto aprovado em 13 de abril de 2017. 
